\title{
Immunoexpression of p53 and ki-67 correlated with clinicopathological parameters in predicting recurrence of oral squamous cell carcinoma
}

\author{
Biji Babu', Kaveri Hallikeri², Kiran Kumar ${ }^{3}$ \\ 1,2,3 Department of Oral Pathology and Microbiology, SDM College of Dental Sciences \& Hospital, A Constituent Unit of \\ Shri Dharmasthala Manjunatheshwara University, Dharwad - 580 009, Karnataka, India
}

Background: Prognosis of oral squamous cell carcinoma (OSCC) can be predicted by evaluating both clinicopathological parameters and molecular markers. Understanding the reasons of recurrence is important to increase the morbidity and mortality of the patient. Aims and Objectives: The objectives are to study the immunoexpression of p53 and $\mathrm{Ki}-67$ in recurrent and non recurrent OSCC. And correlate the clinicopathological parameters among non-recurrent and recurrent OSCC to predict the prognosis of OSCC. Materials and Methods: Clinicopathological and immunoexpression of p53 and Ki-67 at the histologically negative margin (HNM) and invasive tumor front (ITF) were assessed in 50 cases of non-recurrent and recurrent OSCC. Overall survival and disease free survival was estimated. Statistical tests like Mann Whitney $U$ test, $t$ Test, Pearson correlation coefficient, Kaplan Meier curve and Log Rank test were used. Results: The Labelling Index (LI) of p53 and Ki-67 was marginally higher in recurrent than in non-recurrent OSCC cases. When compared with clinicopathologic parameters, non-recurrent OSCC cases showed no significance with p53 LI in margin and ITF except for site, muscle invasion, pattern of invasion (POI) and muscle invasion, whereas in recurrent OSCC cases p53 LI in HNM and ITF did not show any statistical significance except for duration. In both groups, OS and DFS was higher in patients with lesser LI while higher in the greater LI but more number of deaths occurred in this category respectively. Conclusion: To conclude p53 and Ki-67 positivity in the HNM and ITF of non-recurrent and recurrent OSCC was seen and thus can be an important marker for identification of high and low risk individuals.

Key words: Disease free survival; Histologically negative margin; Invasive tumor front; Non-recurrent; Overall survival; Recurrent; Survival rate

\section{INTRODUCTION}

Oral squamous cell carcinoma (OSCC) is the most common malignant tumor in Head \& Neck region. Standard treatment for OSCC is surgery, radiation or both, and is sometimes combined with chemotherapy in advanced diseases. Despite the advent of newer treatment, its 5 -year survival rate is around $50-60 \%$ due to locoregional recurrences. ${ }^{1}$ The invasive tumor front (ITF) has been studied widely which shows a lower degree of differentiation and a greater grade of cellular dissociation in comparison with other parts of the tumor. It is believed that the essential prognostic information about the tumor's invasive and metastatic ability can be deduced from ITF, where the deepest and apparently aggressive cells reside. ${ }^{2}$ Apart from ITF, the presence of tumor in the adjacent margin is related with the high rate of OSCC relapses and shorter overall survival rate. ${ }^{3}$

p53 tumor suppressor gene has been found mutated in more than $50 \%$ of human cancers, and can be useful 
indicator to predict the recurrence of OSCC. ${ }^{4}$ Presence of mutated p53 in tumor adjacent epithelium and invasive tumor front of recurrent patients represent a risk marker of neoplastic recurrence of OSCC as reported in a study. ${ }^{5} \mathrm{Ki}$ 67 is the proliferative human nuclear antigen which is expressed during G1, S, G2, M phases of cell cycle but absent in quiescent G0. Several studies have shown that it's a good surrogate marker for the loss of heterozygosity when applied to the non-neoplastic mucosa surrounding a primary OSCC. ${ }^{6}$ Thus, expression of p53 and Ki-67 in both ITF and HNM could act as a sensitive marker for detection of molecular alterations along with the clinicopathological parameters in predicting recurrences of OSCC.

\section{MATERIALS AND METHODS}

Patient selection- A total of 50 patients with OSCC who underwent tumor resection were retrospectively studied. Out of 50 cases, 25 were NRec cases without locoregional recurrence in a span of 3 years post-surgical treatment while the Rec cases included the cases without recurrence. Both the ITF and HNM were studied. Postoperative follow-up information including tumor recurrence and survival was obtained from the clinical records. Overall survival (OS) time was defined as time the patient stayed alive from the date of OSCC diagnosis to the end of the study or to death. Disease-free survival (DFS) time was defined as time from the date of diagnosis to the date of local recurrence or newly diagnosed metastasis.

Clinicopathological analyses- The clinical parameters included age, gender, habit, site, duration of recurrence and treatment. TNM staging was confirmed based on the American Joint Committee on Cancer staging system. ${ }^{7}$ Histological parameters included the grading, tumor thickness (TTT), pattern of invasion (POI), lymph node metastasis (LNM), margin positivity and submucosal infiltration in the form of perivascular, perineural, muscle were documented.

Immunohistochemical analyses- The tissue sections of $4 \mu \mathrm{m}$ was deparaffinised, rehydrated and blocked with $3 \%$ hydrogen peroxide. Heat induced antigen retrieval was performed in Tris-EDTA Buffer (10mM), $\mathrm{pH}=9.0$ using pressure cooker. The sections were incubated with mouse monoclonal antibody p53 (BP-53-12, PM 101 6ML) and Ki-67 (GM 001-PM 096-6ML) Gene Pulse Scientific, Bangalore, India.Sections were then incubated super sensitive polymer - HRP detection system. Immunoreactivity was revealed by adding diaminobenzidine (DAB). Sections were counterstained with hematoxylin, dehydrated and mounted.
Quantification methods- A total of 500 cells were counted in $40 \mathrm{X}$ magnification in different representative field using an eyepiece graticule with positive staining cells at the ITF and HNM. (Figures 1,2) The labelling index (LI) was calculated by dividing the number of positive cells by the total number of cells and multiplying by 100 .

Statistical analysis- The data were analyzed by means of IBM SPSS Statistics 20.O software. Clinicopathological parameters were compared using Mann Whitney U Test. The comparison of expression of p53 and Ki-67 in HNM and ITF was done using t Test. The clinicopathological parameters were compared with the LI of p53 and Ki-67 in HNM and ITF using Pearson correlation coefficient. Inter observer variability was assessed using Kappa Statistics. The treatment and LI of p53 and Ki-67 were compared with overall and disease free survival using Log Rank Test and Kaplan Meier Curve. $\mathrm{p}<0.05$ was considered significant.

\section{RESULTS}

\section{Clinicopathological parameters}

Clinicopathological parameters between both the groups are described in Table 1. Occurrence of OSCC showed a statistical significant correlation between sites in both the groups $(\mathrm{p}=0.033)$. Tumor thickness and muscle invasion showed a statistical association when compared between the groups $(p=0.010)$. Muscle invasion had a significant correlation $(\mathrm{p}=0.016)$. A statistically highly significant association was observed with respect to treatment in both the groups $(\mathrm{p}=0.001)$.

\section{p53 and Ki-67 expression in HNM and ITF of NRec} and Rec OSCC

The LI of p53 and Ki-67 in HNM and ITF were higher in Rec OSCC in comparison to NRec OSCC. However, a statistical association of LI wasn't found between the 2 groups. (Table 2) The LI of p53 and Ki-67 was demonstrated to be higher in the ITF than in HNM in both groups and was statistically significant $(\mathrm{p}=0.001)$ as listed in Table 3. Two pathologists examined the LI of p53 and Ki-67 in margin and ITF independently and kappa (k) statistics was considered to avoid interobserver bias. (Table 4).

Comparison of LI of p53 and Ki-67 in HNM and ITF with clinicopathological parameters

Pearson correlation coefficient showed relation between the clinicopathological parameters with LI of p53 and Ki-67 in margin and ITF, out of the parameters only habits, site, staging, muscle invasion, pattern of invasion and duration of recurrence showed a statistical significance as given in Table 5 . 


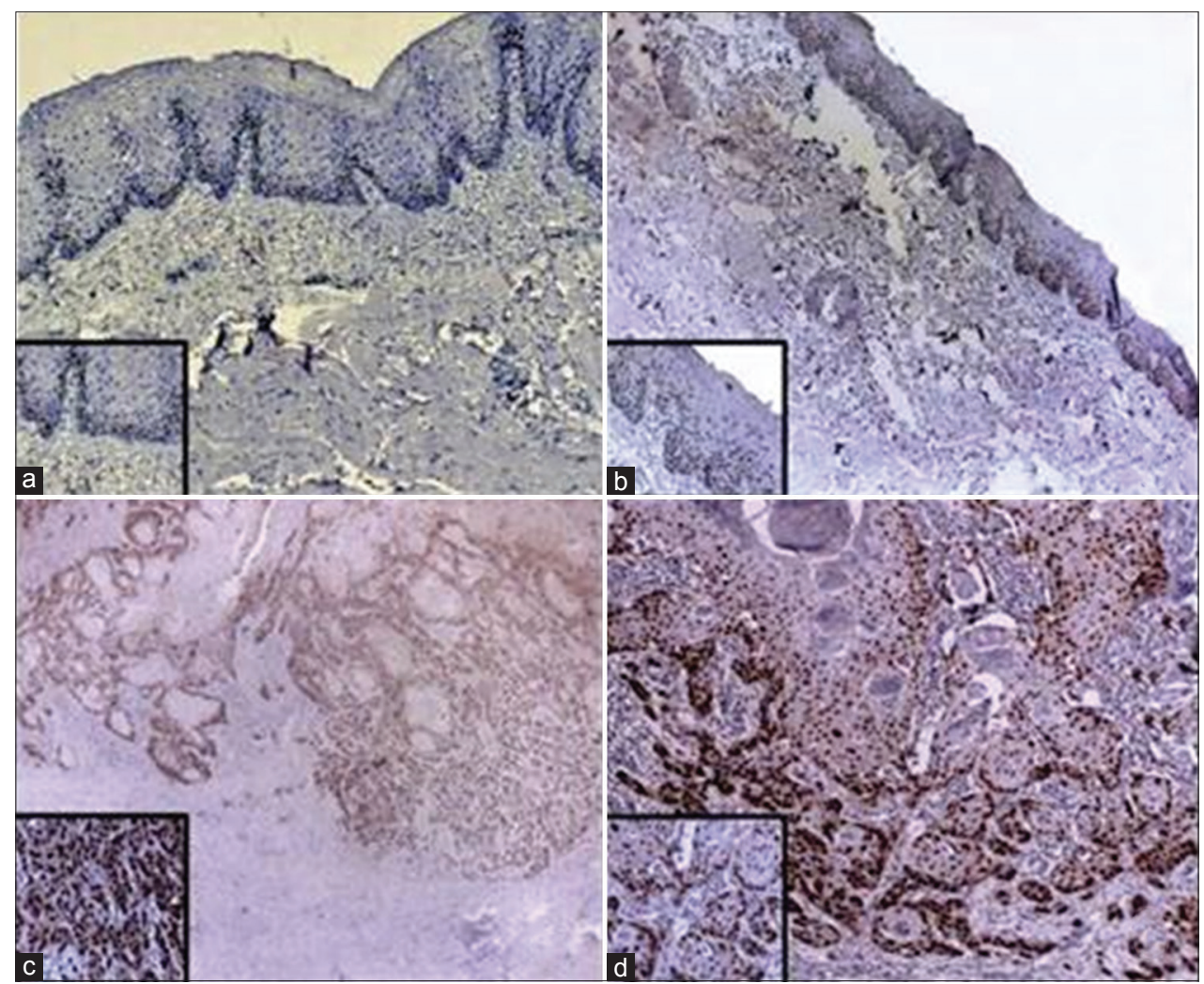

Figure 1: p53 (a,c) and Ki-67 (b,d) expression in HNM and ITF respectively in Recurrent OSCC (x10, x5) (Immunostaining: DAB chromogen, p53 and Ki-67 monoclonal antibody).

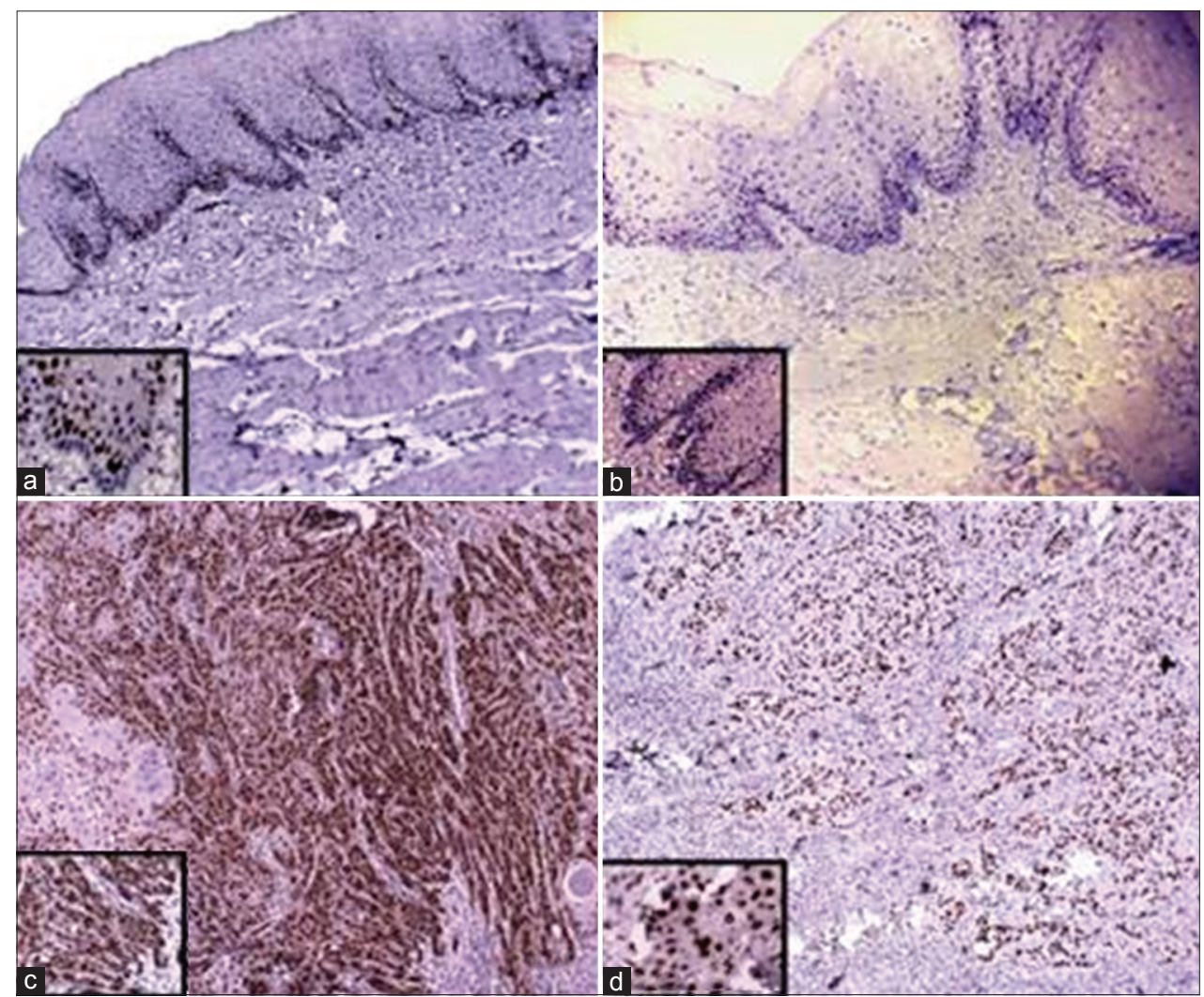

Figure 2: p53 (a,c) and Ki-67 (b,d) expression in HNM and ITF respectively in Non-recurrent OSCC (x10, x5) (Immunostaining: DAB chromogen, p53 and Ki-67 monoclonal antibody). 


\begin{tabular}{|c|c|c|c|c|}
\hline Parameters & Category & $\begin{array}{l}\text { Non- } \\
\text { recurrent } \\
\text { OSCC }\end{array}$ & $\begin{array}{l}\text { Recurrent } \\
\text { OSCC }\end{array}$ & $p$ value \\
\hline \multirow[t]{2}{*}{ Age } & $<40 \mathrm{yrs}$ & $4(16.0)$ & $6(24.0)$ & 0.484 \\
\hline & $>40 \mathrm{yrs}$ & $21(84.0)$ & $19(76.0)$ & \\
\hline \multirow[t]{2}{*}{ Gender } & Male & $22(88.0)$ & $23(92.0)$ & 0.641 \\
\hline & Female & $3(12.0)$ & $2(8.0)$ & \\
\hline \multirow[t]{3}{*}{ Habits } & Nil & $3(12.0)$ & $5(20.0)$ & 0.253 \\
\hline & Tobacco & $19(76.0)$ & $19(76.0)$ & \\
\hline & Combination & $3(12.0)$ & $1(4.0)$ & \\
\hline \multirow[t]{3}{*}{ Site } & $\begin{array}{l}\text { Buccal } \\
\text { mucosa }\end{array}$ & $19(76.0)$ & $11(44.0)$ & 0.033 \\
\hline & Tongue & $2(8.0)$ & $6(24.0)$ & \\
\hline & Others & $4(16.0)$ & $8(32.0)$ & \\
\hline \multirow[t]{3}{*}{ Staging } & Stage I & $6(24.0)$ & $8(32.0)$ & 0.904 \\
\hline & Stage II & $17(68.0)$ & $12(48.0)$ & \\
\hline & Stage III & $2(8.0)$ & $5(20.0)$ & \\
\hline $\mathrm{H} / \mathrm{P}$ & Well & $18(72.0)$ & $19(76.0)$ & 0.750 \\
\hline Grading & Moderate & $7(28.0)$ & $6(24.0)$ & \\
\hline \multirow[t]{3}{*}{$\mathrm{TT}$} & $0-5 \mathrm{~mm}$ & $11(44.0)$ & $4(16.0)$ & 0.010 \\
\hline & $6-10 \mathrm{~mm}$ & $12(48.0)$ & $13(52.0)$ & \\
\hline & $11-15 \mathrm{~mm}$ & $2(8.0)$ & $8(32.0)$ & \\
\hline \multirow{2}{*}{$\begin{array}{l}\text { Muscle } \\
\text { invasion }\end{array}$} & No & 4 (16.0) & $12(48.0)$ & 0.016 \\
\hline & Yes & $21(84.0)$ & $13(52.0)$ & \\
\hline \multirow[t]{2}{*}{ PNI } & No & $23(92.0)$ & $18(72.0)$ & 0.068 \\
\hline & Yes & $2(8.0)$ & $7(28.0)$ & \\
\hline \multirow[t]{2}{*}{ PVI } & No & $24(96.0)$ & $23(92.0)$ & 0.556 \\
\hline & Yes & $1(4.0)$ & $2(8.0)$ & \\
\hline \multirow[t]{2}{*}{ LNM } & Positive & $10(40.0)$ & $10(40.0)$ & 1.000 \\
\hline & Negative & $15(60.0)$ & $15(60.0)$ & \\
\hline \multirow[t]{4}{*}{ POI } & 1 & $4(16.0)$ & $3(12.0)$ & 0.215 \\
\hline & 2 & $8(32.0)$ & $6(24.0)$ & \\
\hline & 3 & $11(44.0)$ & $10(40.0)$ & \\
\hline & 4 & $2(8.0)$ & $6(24.0)$ & \\
\hline \multirow[t]{2}{*}{ Treatment } & $\begin{array}{c}\text { Surgery } \\
\text { without adjunct } \\
\text { therapy }\end{array}$ & $1(4.0)$ & $8(32.0)$ & $<0.001$ \\
\hline & $\begin{array}{l}\text { Surgery } \\
\text { with adjunct } \\
\text { therapy }\end{array}$ & $24(96.0)$ & $17(68.0)$ & \\
\hline \multirow[t]{2}{*}{ Margin +ve } & Clear & $9(36.0)$ & $9(36.0)$ & 0.111 \\
\hline & Involved & $16(64.0)$ & $16(64.0)$ & \\
\hline \multirow[t]{3}{*}{ Duration } & $<1$ year & - & $18(72.0)$ & \\
\hline & $1-2 \mathrm{yrs}$ & - & $5(20.0)$ & \\
\hline & $>2 \mathrm{yrs}$ & - & $2(8.0)$ & \\
\hline
\end{tabular}

Comparison of survival analysis with treatment modality and labelling index using Kaplan Meier \& Log rank test The treatment modalities used for treating conventional OSCC were either Surgery or a combination of Surgery and Radiotherapy or chemotherapy was used to predict OS and DFS in 2 groups showed similar OS with more number of deaths occurred in a shorter span of time in Rec OSCC whereas a greater DFS was seen in NRec OSCC as compared to Rec OSCC. (Figure 3).

To predict the survival outcome in patients between the 2 groups, the 3 year OS and DFS were compared to the LI

\begin{tabular}{|c|c|c|c|c|c|}
\hline Markers & Groups & Mean & SD & $t$ value & Significance \\
\hline \multirow[t]{2}{*}{ p53ITF } & $\begin{array}{l}\text { Non- } \\
\text { recurrent } \\
\text { OSCC }\end{array}$ & 44.25 & 29.65 & 0.063 & 0.950 \\
\hline & $\begin{array}{l}\text { Recurrent } \\
\text { OSCC }\end{array}$ & 44.78 & 29.81 & & \\
\hline \multirow[t]{2}{*}{$\begin{array}{l}\text { p53 } \\
\text { margin }\end{array}$} & $\begin{array}{l}\text { Non- } \\
\text { recurrent } \\
\text { OSCC }\end{array}$ & 19.61 & 13.00 & 0.003 & 0.998 \\
\hline & $\begin{array}{l}\text { Recurrent } \\
\text { OSCC }\end{array}$ & 19.63 & 14.48 & & \\
\hline \multirow[t]{2}{*}{$\begin{array}{l}\text { Ki-67 } \\
\text { ITF }\end{array}$} & $\begin{array}{l}\text { Non- } \\
\text { recurrent } \\
\text { OSCC }\end{array}$ & 63.26 & 9.99 & 0.934 & 0.355 \\
\hline & $\begin{array}{l}\text { Recurrent } \\
\text { OSCC }\end{array}$ & 66.17 & 11.94 & & \\
\hline \multirow[t]{2}{*}{$\begin{array}{l}\text { Ki-67 } \\
\text { margin }\end{array}$} & $\begin{array}{l}\text { Non- } \\
\text { recurrent } \\
\text { OSCC }\end{array}$ & 21.51 & 7.85 & 0.608 & 0.546 \\
\hline & $\begin{array}{l}\text { Recurrent } \\
\text { OSCC }\end{array}$ & 22.85 & 7.70 & & \\
\hline
\end{tabular}

\begin{tabular}{|c|c|c|c|c|c|}
\hline Group & Markers & Mean & SD & $t$ value & Significance \\
\hline \multirow{2}{*}{$\begin{array}{l}\text { Non- } \\
\text { recurrent } \\
\text { OSCC }\end{array}$} & $\begin{array}{l}\text { p53 LI } \\
\text { (ITF) }\end{array}$ & 44.25 & 29.65 & \multirow[t]{2}{*}{3.805} & \multirow[t]{2}{*}{$<0.001$} \\
\hline & $\begin{array}{l}\text { P53 LI } \\
\text { (margin) }\end{array}$ & 19.61 & 13.00 & & \\
\hline \multirow{2}{*}{$\begin{array}{l}\text { Non- } \\
\text { recurrent } \\
\text { OSCC }\end{array}$} & $\begin{array}{l}\text { Ki-67 LI } \\
\text { (ITF) }\end{array}$ & 63.26 & 9.99 & \multirow[t]{2}{*}{16.419} & \multirow[t]{2}{*}{$<0.001$} \\
\hline & $\begin{array}{l}\text { Ki-67 LI } \\
\text { (margin) }\end{array}$ & 21.51 & 7.85 & & \\
\hline \multirow[t]{2}{*}{$\begin{array}{l}\text { Recurrent } \\
\text { OSCC }\end{array}$} & $\begin{array}{l}\text { p53 LI } \\
\text { (ITF) }\end{array}$ & 44.78 & 29.81 & \multirow[t]{2}{*}{3.795} & \multirow[t]{2}{*}{$<0.001$} \\
\hline & $\begin{array}{l}\text { p53 LI } \\
\text { (margin) }\end{array}$ & 19.63 & 14.48 & & \\
\hline \multirow[t]{2}{*}{$\begin{array}{l}\text { Recurrent } \\
\text { OSCC }\end{array}$} & $\begin{array}{l}\text { Ki-67 LI } \\
\text { (ITF) }\end{array}$ & 66.17 & 11.94 & \multirow[t]{2}{*}{15.237} & \multirow[t]{2}{*}{$<0.001$} \\
\hline & $\begin{array}{l}\text { Ki-67 LI } \\
\text { (margin) }\end{array}$ & 22.85 & 7.70 & & \\
\hline
\end{tabular}

of p53 and Ki-67. (Figure 4) The cut off value for p53 was taken estimate OS and DFS in accordance to various studies i.e $<10,>10$ and median of $\mathrm{Ki}-67$ were evaluated in both HNM and ITF. In NRec OSCC, a statistical significance was observed between p53 LI in ITF and OS, p53 margin and DFS, Ki-67 LI in ITF and OS, Ki-67 ITF and DFS. In Rec OSCC, a statistical significance was obtained between $\mathrm{Ki}-67$ in margin and OS and since none of the recurrent cases were disease free from the time of primary treatment to the 3 year span of post-operative follow up, no statistics could be computed. (Table 6). 


\section{DISCUSSION}

In OSCC, anatomical site is considered as one of the important parameter to predict prognosis and survival rate. In the present study, a statistical significance was observed in relation to site among the 2 groups. The occurrence of OSCC in buccal mucosa can be attributable to the use of smokeless tobacco prevalent in the local area. The second predominant site associated was tongue. Cancers of tongue have high recurrences due to the rich lymphatic network, higher chemical carcinogen metabolization and high permeability due to thin nonkeratinized epithelium. ${ }^{7}$ Other sites affected in the present study included retromolar trigone, floor of mouth and alveolus. Anatomical limits and difficult access reduce the possibility for wide resection margins in sites such as oropharynx and retromolar trigone thereby causing incomplete removal of tumor.

Table 4: Measurement of agreement between the two observers for p53 and Ki-67 in margin and ITF

\begin{tabular}{lcc}
\hline & Kappa value & Approx sig \\
\hline p53 ITF & 0.624 & $<0.001$ \\
Ki-67 ITF & 0.409 & 0.003 \\
p53 margin & 0.722 & $<0.001$ \\
Ki-67 margin & 0.602 & $<0.001$ \\
\hline
\end{tabular}

T'T may exert influence on the survival rates. ${ }^{8}$ In our study, TT was seen to be greater in the recurrent group and a statistical significance was observed. Brandwein-Gensler et al showed PNI (of nerves $>1 \mathrm{~mm}$ in diameter) was significantly associated with increased local recurrence. ${ }^{9}$ In our study PNI didn't show a statistical significance to predict recurrence but 7 cases out of total 9 showed recurrences. A greater number of recurrent cases had undergone only surgery with no adjunct therapy than the patients who underwent adjunct radiotherapy. A high statistical significance was noted between the 2 groups.

The positivity for $\mathrm{p} 53$ in OSCC varies in different studies from $0-100 \% .{ }^{10}$ In NRec and Rec OSCC, p53 LI in ITF was $[(44.25 \pm 29.65),(44.78 \pm 29.51)]$ whereas in HNM it was $[(19.61 \pm 13),(19.63 \pm 14.48)]$ respectively whereby no statistical association was found between them. In this study, both NRec and Rec OSCC showed higher p53 LI in ITF in comparison to HNM which is indicative of noticeable accumulation of $\mathrm{p} 53$ positive cells at the ITF of tumors due to the presence of amplified and uninhibited cell proliferation at ITF accumulating essential genetic alterations for invasion and metastasis.

Oliveira et al., didn't find any correlation between p53 and $\mathrm{Ki}-67$ in ITF and HNM whereas in our study the recurrent

Table 5: Comparison of p53 and Ki-67 LI in margin and ITF between NRec and Rec OSCC clinicopathological parameters

\begin{tabular}{|c|c|c|c|c|c|c|c|}
\hline Groups & Region & Habits & Site & Staging & Muscle invasion & POI & Duration of recurrence \\
\hline \multirow[t]{4}{*}{ Non-Recurrent OSCC } & P53 Margin & 0.850 & 0.045 & 0.514 & 0.14 & 0.036 & \\
\hline & $\begin{array}{l}\text { P53 } \\
\text { ITF }\end{array}$ & 0.957 & 0.092 & 0.606 & 0.034 & 0.004 & \\
\hline & Ki-67 Margin & 0.517 & 0.918 & 0.634 & 0.516 & 0.695 & \\
\hline & Ki-67 ITF & 0.851 & 0.066 & 0.223 & 0.201 & 0.926 & \\
\hline \multirow[t]{4}{*}{ Recurrent OSCC } & P53 Margin & 0.256 & 0.772 & 0.738 & 0.078 & 0.791 & 0.034 \\
\hline & $\begin{array}{l}\text { P53 } \\
\text { ITF }\end{array}$ & 0.662 & 0.782 & 0.753 & 0.068 & 0.614 & 0.046 \\
\hline & Ki-67 Margin & 0.014 & 0.202 & 0.056 & 0.597 & 0.041 & 0.449 \\
\hline & Ki-67 ITF & 0.977 & 0.074 & 0.003 & 0.525 & 0.550 & 0.268 \\
\hline
\end{tabular}

$p<0.05$

Table 6: Comparison of p53 and Ki-67 LI with OS and DFS

\begin{tabular}{|c|c|c|c|c|c|c|}
\hline \multirow[t]{2}{*}{ Groups } & \multirow[t]{2}{*}{ Marker } & \multirow[t]{2}{*}{ Cut off limit } & \multicolumn{2}{|c|}{ Confidence Interval (CI) } & \multicolumn{2}{|c|}{ Log rank (Mantel Cox) } \\
\hline & & & Upper & Lower & Chi square & Sig \\
\hline \multirow[t]{7}{*}{ Non-recurrent OSCC } & p53 margin\&DFS & $1=<10$ & 39.07 & 45.58 & 6.228 & 0.013 \\
\hline & p53 ITF \& OS & & 39.43 & 45.36 & 6.039 & 0.014 \\
\hline & & & 35.01 & 38.66 & & \\
\hline & Ki-67 ITF \& OS & $1=<65.2$ & 34.44 & 38.72 & 5.284 & 0.022 \\
\hline & & $2=>65.2$ & 36.72 & 42.10 & & \\
\hline & Ki-67ITF \& DFS & & 34.52 & 38.79 & 4.697 & 0.030 \\
\hline & & & 38.13 & 43.42 & & \\
\hline \multirow[t]{2}{*}{ Recurrent OSCC } & $\mathrm{Ki}-67$ margin \& OS & $1=<24.2$ & 37.76 & 44.90 & 3.638 & 0.050 \\
\hline & & $2=>24.2$ & 27.45 & 38.96 & & \\
\hline
\end{tabular}




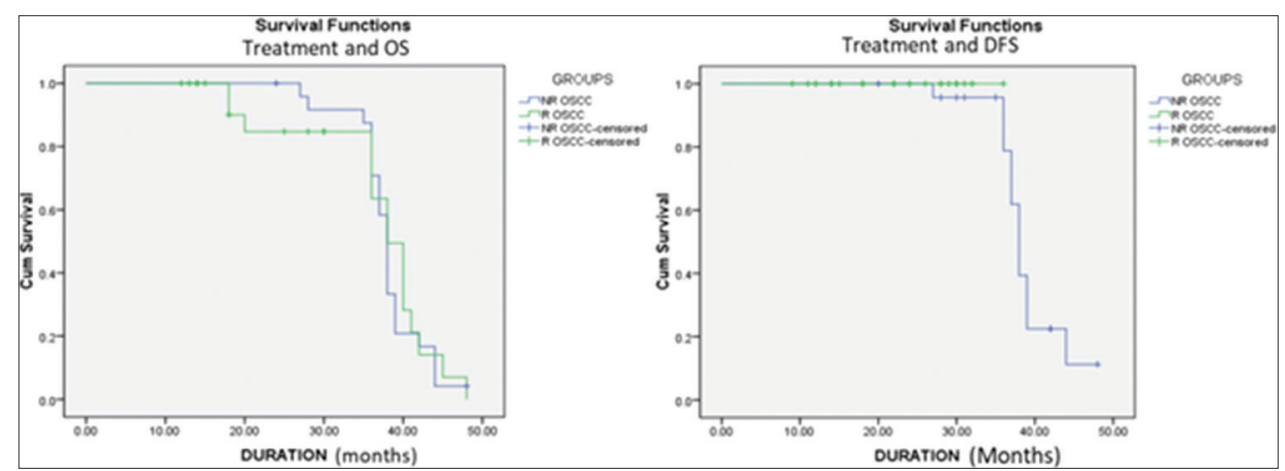

Figure 3: Kaplan- Meier curve showing comparison of treatment with OS and DFS between NRec and Rec OSCC.

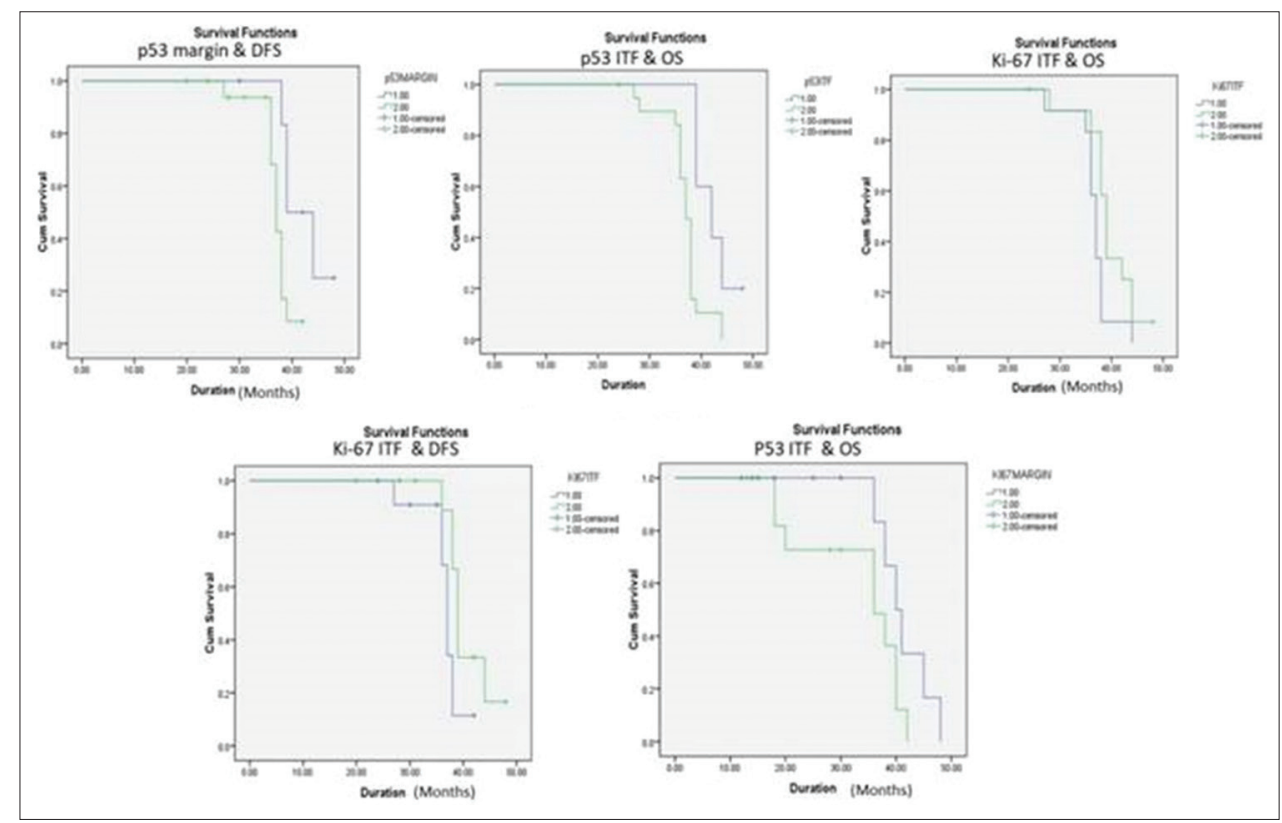

Figure 4: Kaplan- Meier curve showing survival in NRec cases (a,b,c,d) and Rec OSCC.

category had a marginal increase in expression. ${ }^{5}$ Kato et al., suggested that highly invasive tumors exhibit p53 mutation and PCNA activity, thereby increasing the proliferative capacity at the ITF of OSCC with increased chances of recurrence and therefore a worse prognosis. ${ }^{11} \mathrm{In}$, addition investigators must set an arbitrary threshold of the percentage of stained cells that will be used to characterise sections as positive or negative. ${ }^{12}$ Recent studies have set this threshold at $10 \%$ stained cells. ${ }^{13}$ Hence, in NRec OSCC, p53 overexpression in ITF was seen in (20/25) cases while in recurrent OSCC it was (18/25). Similar range of $\mathrm{p} 53$ overexpression was observed by GonzalezMoles. ${ }^{14}$ Whereas median value of proliferative index was used to classify Ki-67 positive and Ki-67 negative. ${ }^{15}$ In NRec OSCC, the median value of LI in margin was 21.2 and ITF was 65.2 while in Rec group the median value of LI in margin was 24.2 and ITF was 69.56. In NRec OSCC, margin and ITF showed overexpression of Ki-67 in (13/25) and $(14 / 25)$ cases whereas in Rec OSCC overexpression was seen in (13/25) and (15/25) cases respectively.
In the present study, 12 tumors were negative for p53 which could be attributable to non-sense and frame-shift mutations of p53 gene leading to deletion or truncation of the protein, hence do not show detectable levels of p53 protein immunohistochemically or loss of p53 activity due to gross deletion that abolishes all $\mathrm{p} 53$ protein production and also, tumors that follow different carcinogenic pathways in which the p53 abrogation does not play a role can be a reason for negative expression of $\mathrm{p} 53 .{ }^{16}$

In NRec and Rec OSCC, Ki-67 expression in ITF was $[(63.26 \pm 9.99),(66.17 \pm 11.94)]$ whereas in HNM it was $[(21.51 \pm 7.85),(22.85 \pm 7.70)]$ no statistical association was found between the groups respectively. A highly statistical significance was noted between p53 and Ki-67 in HNM and p53 in ITF within the NRec and Rec groups.

Montebugnoli et al, study showed Ki-67 protein was significantly correlated with loss of heterozygosity in the 
oral mucosa surrounding OSCC and as advocated as a good predictor marker. Also showed a positive expression at ITF. ${ }^{17}$

Clinicopathological parameters were compared with the labelling index of p53 and Ki-67 in HNM and ITF. A study by Oliveira et al didn't demonstrate any statistically significant value in the evaluation of clinicopathological parameters between NRec and Rec OSCC in contrast to our study in which site, habit, staging, muscle invasion, POI, duration of recurrence showed a significant statistical association. $^{5}$

Cooper et al have also reported that postoperative radiotherapy and chemotherapy can improve DFS and improve local and regional control rate in patients with OSCC. ${ }^{18}$ On comparison of survival rate between NRec and Rec OSCC, it was observed that OS in NRec OSCC was 48 months with overall good prognosis with 2 deaths whereas in Rec OSCC the 8 patients died between 10 months to 30 months.

The 3 year OS and DFS were compared to the LI of p53 and $\mathrm{Ki}-67$ to assess their role in predicting the survival outcome. In NRec OSCC, it was observed that the cases with a higher p53 and Ki-67 index in margin and ITF had a reduced OS and DFS whereas the cases with a lesser nuclear expression had an increased OS. In the present study, LI of p53 and Ki-67 was associated with the survival of the patients whereas Koelbl et al \& Bettendorf et al in their study have reported no association of proliferative markers like Ki-67, p53, PCNA and survival in OSCC. ${ }^{19,20}$ Since none of the recurrent cases were disease free from the time of primary treatment to the 3 year span of postoperative follow up, no statistics could be computed.

Our study included limitations like long term follow ups should be done for the cases showing tumor suppressor gene mutation and higher proliferative index. Single margin cannot be a representative of entire tumor, number of samples can be increased. Standardized procedure has to be adapted in obtaining margins according to site specificity and combination of other proliferative markers to predict recurrences such as MCM2, Geminin, PCNA etc.

\section{CONCLUSION}

The current study described p53 and Ki-67 positivity in histologically negative margin and invasive tumor front in both the groups. Few clinicopathological parameters showed association with p53 and Ki-67 positivity. Overexpression of these two markers was related to the prognosis and survival.
Thus, with the application of molecular methods in conjugation with routine $\mathrm{H} \& \mathrm{E}$ staining \& IHC could lead to a better understanding of the biologic nature of OSCC, long term survival rate, and more selective preoperative management. Further investigations may provide more insights to this interesting field of study with long term follow ups. Only one negative margin was studied and standardized procedure has to be adapted in obtaining margins according to site specificity and combination of other proliferative markers to predict recurrences such as MCM2, Geminin, PCNA etc.

\section{REFERENCES}

1. Listl S, Jansen L, Stenzinger A, Freier K, Emrich K, Holleczek B, et al. Survival of patients with oral cavity cancer in Germany. PLoS One 2013; 8: e53415.

2. Bryne M. Is the invasive front of an oral carcinoma the most important area for prognostication? Oral Dis 1998;4:70-77.

3. Carvahlo AD, Kowalski LP, Campos AHJFM, Soares FA, Carvahlo AL and Vettore AL. Clinical significance of molecular alterations in histologically negative surgical margins of head and neck cancer patients. Oral Oncol 2012; 48:240-248.

4. Bai L and Zhu WG. p53: Structure, Function and Therapeutic Applications. J of Cancer Molecules 2006; 2:141-153.

5. Oliveira MVMD, Fraga CADC, Pereira CS, Barros LO, Oliveria ES, Guimaraes ALS, et al. Field Cancerization in Head and Neck SCC: Immunohistochemical expression of p53 and Ki67 proteins, a clinicopathological study. Rev Clin Pesq Odontol 2010; 6:17-27.

6. Greene FL, Page DL, Fleming ID, Fritz AG, Balch CM, Haller DG, et al. AJCC Cancer Staging Manual, $6^{\text {th }}$ Edition 2002. New York: Springer.

7. An SY, Jung EJ, Lee M, Kwon TK, Sung MW, Jeon YK, et al. Factors related to regional recurrence in Early Stage Squamous Cell Carcinoma of the Oral Tongue. Clinical Exper Otorhinolaryngol 2008;1:166-170.

8. Massano J, Regateiro F and Jauario G. Oral Squamous Cell Carcinoma: Review of prognostic and predictive factors. Oral Surg Oral Med Oral Pathol Oral Radiol Endod 2006; 102:67-76.

9. Brandwein-Gensler M, Teixeira MS, Lewis CM, Lee B, Rolnitzky L, Hille JJ, et al. Oral SCC: histologic risk assessment, but not margin status, is strongly predictive of local disease-free and overall survival. Am J Surg Pathol 2005; 29:167-178.

10. Dragomir IP, Simionescu C, Mărgăritescu CL, Stepan A, Dragomir IM and Popescu MR. p53, p16 and Ki67 immunoexpression in oral squamous carcinomas. Rom J Morphol Embryol 2012; 53:89-93.

11. Kato K, Kawashiri S, Yoshizawa K, Kitahara H, Okamune A, Sugiura S, et al. Expression form of p53 and PCNA at the invasive front in oral squamous cell carcinoma: correlation with clinicopathological features and prognosis. J Oral Pathol Med 2011; 40:693-698.

12. Laccourreye O, Hans S, Menard M, Garcia D, Brasnu D and Holsinger FC. Transoral lateral oropharyngectomy for squamous cell carcinoma of the tonsillar region: II. An analysis of the incidence, related variables, and consequences of local recurrence. Arch Otolaryngol Head Neck Surg 2005; 131:592-599.

13. Yanamoto S, Kawasaki G, Yoshitomi I and Mizuno A. p53, Mdm2 and p21 expression in oral squamous cell carcinomas: relationship with clinicopathologic factors. Oral Surg Oral Med 
Oral Pathol Oral Radiol Endod 2002; 94:593-600.

14. Gonzalez-Moles MA, Galindo P, Gutierrez-Fernandez JO Sanchez-Fernandez E, Rodriguez-Archilla A and Ruiz-Avila I. P53 Protein Expression in Oral Squamous Cell Carcinoma. Survival analysis. Anticancer Res 2001; 21:2889-2894.

15. Pyke C, Kristensen P and Ralfkiar E. Urokinase type plasminogen activator in expressed stromal cells and receptor in cancer cells at invasive foci in human colon adenocarcinomas. Am J Patho 1991; 138:1059-1067.

16. Azizi SA, NFS NM, Sailan AT, Ajura AJ and Ibrahim N. Expression of P53 and P16 at Tumour Invasive Front in Oral Squamous Cell Carcinoma (OSCC). Cosmetol \& Oro Facial Surg 2016; 2:105-109.

17. Montebugnoli L, Gissi DB, Badiali G, Marchetti C, Cervellati F adnd Fernadi A. Ki-67 from clinically and histologically "normal"
Distant mucosa as prognostic marker in early stage (T1-T2 N0) Oral Squamous Cell Carcinoma: a prospective study. J Oral Maxillofac Surg 2011; 69:2579-2584.

18. Cooper JS, Pajak TF, Forastiere AA, Jacobs J, Campbell BH, Saxman SB, et al. Postoperative concurrent radiotherapy and chemotherapy for high-risk squamous-cell carcinoma of the head and neck. N Engl J Med 2004; 50:1937-1944.

19. Koelbl O, Rosenwald A, Haberl M, Müller J, Reuther J and Flentje M. p53 and $\mathrm{Ki}-67$ as predictive markers for radiosensitivity in squamous cell carcinoma of the oral cavity? an immunohistochemical and clinicopathologic study. Int J Radiation Oncology Biol Phys 2001;49:147-154.

20. Bettendorf $\mathrm{O}$ and Herrmann G. Prognostic relevance of Ki67 antigen expression in 329 cases of oral squamous cell carcinoma. Otolaryngology 2002; 64:200-205.

Authors Contribution:

BB- Conceptualized study, literature search, statistically analyzed and interpreted, prepared first draft of manuscript and critical revision of the manuscript;

$\mathrm{KH}$ - Concept and design of the study, reviewed the literature, manuscript preparation, critical revision of the manuscript; statistically analyzed and interpreted;

KK- Concept and design of the study, revision of manuscript and review of study.

Work attributed to:

Department of Oral Pathology and Microbiology, SDM College of Dental Sciences and Hospital

Orcid ID:

Dr. Kaveri Hallikeri- (D) https://orcid.org/0000-0002-5776-7478

Source of Support: None, Conflict of Interest: None. 